\title{
Myocardial infarction in the absence of obstructive coronary artery disease (MINOCA): A Challenge to Diagnose and Manage
}

Meera D Kondapaneni*, Ahmad Jabri, Aisha Siraj and Saima Karim

Heart and Vascular Institute, MetroHealth Medical Center / Case Western Reserve University, 2500 MetroHealth Dr, Cleveland, OH, USA, 44109

*Corresponding Author: Meera D Kondapaneni, Heart and Vascular Institute, MetroHealth Medical Center / Case Western Reserve University, 2500 MetroHealth Dr, Cleveland, OH, USA.

Received Date: November 20, 2020; Accepted Date: December 08, 2020; Published Date: December 16, 2020

Citation: Meera D Kondapaneni, Ahmad Jabri, Aisha Siraj and Saima Karim., (2020) Myocardial infarction in the absence of obstructive coronary artery disease (MINOCA): A Challenge to Diagnose and Manage.. J. Clinical Cardiology and Cardiovascular Interventions, 3(13); Doi:10.31579/2641-0419/112

Copyright: ( $) 2020$ Meera D Kondapaneni, This is an open-access article distributed under the terms of the Creative Commons Attribution License, which permits unrestricted use, distribution, and reproduction in any medium, provided the original author and source are credited.

Abstract:
Myocardial Infarction in the absence of obstructive coronary artery disease [MINOCA] is seen in 5-6\% of the
patients presenting with myocardial infarction. While patients with MINOCA can present with either ST
segment elevation or non-ST segment elevation myocardial infarction, they are less likely to have ST segment
deviation on electrocardiography and have less of cardiac biomarker elevation compared to their obstructive
coronary artery disease counterparts. Patients with MINOCA are usually younger and with lower prevalence of
traditional cardiovascular risk factors compared with patients presenting with obstructive coronary artery
disease. A variety of atherosclerotic and non-atherosclerotic mechanisms can lead to MINOCA. A diagnosis of
MINOCA can only be made in patients whose clinical presentation is attributed to an ischemic event after
excluding obstructive coronary artery disease and alternate causes for troponin elevation. A systematic approach
to diagnosing the underlying causes is warranted to optimally treat patients presenting with MINOCA.
Key words: myocardial infarction in the absence of obstructive coronary artery disease; minoca;
management

\section{Introduction:}

Myocardial Infarction in the absence of obstructive coronary artery disease [MINOCA] is seen in $5-6 \%$ of the patients presenting with myocardial infarction and is more prevalent in females compared with males. [1][2] The disease entity was first identified 75 years ago when myocardial necrosis was reported in autopsies without the evidence of significant coronary atherosclerosis. [3] Substantial variability exits in the manner patients with suspected MINOCA are evaluated and treated. The present review aims at summarizing the updated definition for the broadly labelled term MINOCA and provide a clinical framework for the evaluation and management of these patients.

\section{Disease epidemiology}

Early angiographic studies by Likoff et. al. and Eliot et. al. reported the paradox of myocardial ischemia and necrosis in patients with normal coronary arteriograms. [4,5] Further angiographic studies by DeWood et. al. reported a prevalence of non-obstructive coronary arteries in nearly $5 \%$ of myocardial infarction patients undergoing angiography. [6] These numbers were further sustained by individual studies and pooled analysis which reported similar prevalence of non-obstructive coronary arteries in myocardial infarction patients undergoing angiography. [2] The disease was initially referred to as myocardial infarction with normal coronary arteries [MINC] but later changed to MINOCA to include patients with atherosclerotic coronary arteries which were not severe enough to compromise myocardial blood flow. [7,8] While patients with MINOCA can present with either ST segment elevation or non-ST segment elevation myocardial infarction, they are less likely to have ST segment deviation on electrocardiography and have a smaller degree of cardiac biomarker elevation compared to their obstructive coronary artery disease counterparts. $[9,10]$ Furthermore, patients with MINOCA are usually younger compared with patients presenting with obstructive coronary artery disease. $[9,10]$ MINOCA is more prevalent in blacks, Maori or Pacific race, and Hispanic ethnicity. [10,11] Traditional risk factors like dyslipidemia, hypertension, diabetes mellitus, tobacco abuse and a family history of myocardial infarction are less prevalent in patients presenting with MINOCA.

\section{Definition}

The European Society of Cardiology drafted the first international position article on MINOCA and defined MINOCA based on Third Universal Definition of Myocardial Infarction. [12,13] A recent scientific statement from the American Heart Association further refined the definition of MINOCA based on Fourth Universal Definition of Myocardial Infarction as: 1) Acute Myocardial Infarction as defined by 
the "Fourth Universal Definition of Myocardial Infarction"; (2) Nonobstructive coronary arteries on angiography, with no lesions $\geq 50 \%$ in a major epicardial vessel (normal coronary arteries, mild luminal irregularities $(<30 \%$ stenoses) or moderate coronary atherosclerotic lesions ( $>30 \%$ but $<50 \%$ stenoses) ; and (3) No specific alternate diagnosis for the clinical presentation where in alternate diagnoses include but are not limited to non-ischemic causes such as sepsis, pulmonary embolism, and myocarditis. [1, 14]

\section{Etiology}

The underlying mechanisms for myocardial necrosis in patients presenting with MINOCA can be broadly classified into atherosclerotic and nonatherosclerotic causes. [1]

\section{Atherosclerotic causes of Myocardial Necrosis}

Atherosclerotic causes of myocardial necrosis are due to plaque disruption which includes plaque rupture, plaque erosion and calcific nodules. [1] Plaque disruption was observed in one-third of the women patients diagnosed with MINOCA. [15] Plaque rupture, typically caused by inflammation, is discontinuity of fibrous cap leading to a communication between plaque cavity and the coronary lumen leading to thrombus formation. Whereas, plaque erosion is primarily caused by endothelial erosion with a thrombus that is contiguous to the luminal surface of a plaque without signs of rupture. [16] Plaque disruption can cause thrombus formation with distal embolization, and in some cases, transient complete thrombosis with spontaneous thrombolysis. [15] Angiographic evidence of occlusion may not be evident due to nonocclusive thrombus in patients with MINOCA.

\section{Nonatherosclerotic causes of Myocardial Necrosis}

Coronary artery vasospasm is defined as intense (>90\%) transient vasospasm of the coronary arteries associated with angina and ischemic electrocardiographic changes either spontaneously or in response to a provocative stimulus as defined by Coronary Vasomotion Disorders International Study Group (COVADIS). [17] Though Prinzmetal et al. first described coronary artery spasms in patients with obstructive coronary artery disease, it is now more often considered in patients with nonobstructive coronary artery disease. [18] Further studies have reported coronary artery vasospasm as the leading cause of MINOCA with evidence for coronary vasospasm reported in nearly $46 \%$ of the patients presenting with MINOCA undergoing provocative tests. [2,19]

The coronary microcirculation which accounts for nearly $70 \%$ of the coronary resistance can potentially contribute to the pathogenesis of MINOCA. Further, coronary artery emboli can result in MINOCA if it involves the coronary microcirculation. Hypercoagulable state secondary to inherited disorders, thrombotic thrombopenic purpura, and heparin induced thrombocytopenia can precipitate embolic phenomenon and lead to occlusion of coronary microcirculation causing MINOCA. Spontaneous coronary artery dissection can be considered a possible cause of MINOCA. [10] Though most patients with spontaneous coronary artery dissection have a visible obstruction on angiography, the arteries can be normal because of the gradual tapering of the vessels. [20] Furthermore, few patients may have a supply-demand mismatch which can present as MINOCA. [21,22]

\section{Management}

The management strategies for patients with myocardial infarction secondary to obstructive causes are well established. However, its counterpart with non-obstructive coronary artery disease management lacks evidence-based guidelines and hence the variable standards in diagnosis and management of MINOCA. Some progress was made in the realm of multi-modality imaging as a tool to identify potential mechanisms leading to MINOCA. Reynolds et. al in a recent prospective, multicenter, observational study demonstrated that Coronary Optical Coherence Tomography (OCT) and Cardiac Magnetic Resonance Imaging (CMR) together can diagnose identifiable etiology in approximately $85 \%$ of women presenting with MINOCA. [23]

Although the prognosis of patients with MINOCA has been shown to be better than their counterparts with obstructive coronary artery disease and presenting with AMI, the mortality and morbidity associated with MINOCA is not negligible and substantially higher than general population without cardiovascular disease. $[1,10]$ A more recent study by Choo et.al on behalf of KAMIR-NIH investigators has revealed that risk of all-cause death and recurrent MI were similar between patients with MINOCA and MI due to obstructive coronary artery disease at 2 years. [24] Hence it is imperative that a systematic approach is needed towards diagnosing this heterogenous entity and further define and treat the underlying cause. Position statements from European Society of Cardiology and American Heart Association provide an excellent framework for diagnosis and management of MINOCA. [1,12]

\section{Diagnosis}

The diagnostic algorithm for MINOCA include an initial evaluation to exclude clinically overt causes for myocardial injury from a non-ischemic event. [1,12] This should be followed by further evaluation to identify potentially overlooked obstructive coronary artery disease by rereviewing the angiogram to rule out distal cut-offs suggesting thromboembolic occlusion and spontaneous coronary artery dissection. Further investigation focusing on individual etiologies for the ischemic event leading to MINOCA can be considered including coronary vascular imaging with Intravascular Ultrasound (IVUS) and OCT to identify plaque disruption, invasive coronary provocative testing to rule out epicardial coronary vasospasm, and coronary functional assessment with Coronary Flow Reserve to assess microvascular function. Furthermore, CMR should be considered in patients with MINOCA to differentiate it from myocarditis, Takotsubo cardiomyopathy and other cardiomyopathies as well as to confirm ischemic etiology with evidence suggestive of infarction. [23]

\section{Individualized treatment strategies}

After excluding all possible alternate diagnoses mimicking AMI and identifying potential underlying mechanism for MINOCA, cause-specific targeted therapy should be considered. [1] MINOCA patients secondary to plaque disruption should be treated with cardioprotective therapies in accordance with the AMI guidelines with aspirin being the main cornerstone of management because the pathophysiology is similar to that of myocardial infarction due to obstructive coronary artery disease. Further, patients with MINOCA are usually not treated with stents, as supported by a study which treated MINOCA patients with dual antiplatelet therapy alone and reported an acceptable 1-year revascularization rate of $5.7 \%$. [25] Calcium channel blockers are the 
mainstay of treatment in patients presenting with MINOCA secondary to coronary spasm. [26, 27] Treating underlying cause remains the mainstay for patients presenting with supply-demand mismatch.

\section{Cardioprotective therapies}

The role of cardioprotective therapies in secondary prevention is not clearly outlined for patients with MINOCA unlike MI with obstructive coronary artery disease with no completed prospective, randomized controlled trials to date. An observational cohort study of patients with MINOCA enrolled in SWEDEHEART registry indicated that angiotensin-converting enzyme inhibitors/angiotensin receptor blockers (ACEI/ARB) and statin therapy were associated with lower major adverse cardiac events defined as all-cause mortality, hospitalization for myocardial infarction, ischemic stroke and heart failure after 4.1 years of mean follow up. [28] Beta-blockers were associated with a trend towards low event rate in the same study whereas dual antiplatelet therapy was not associated with a lower event rate. A multicenter prospective registry by Choo et. al. also confirmed the independent association of nonuse of renin-angiotensin system blockers and statins with an increased risk of all-cause mortality at 2 year follow up. [24] MINOCA-BAT, a multinational, multi-center, randomized clinical trial is currently underway to evaluate the effect of beta-blocker and ACEI/ARB therapy on long-term clinical outcomes in patients with MINOCA. [29]

\section{Conclusion}

A systematic multi-modality approach to diagnosing underlying mechanisms leading to MINOCA and excluding alternate diagnoses of myocardial injury is crucial in establishing this challenging heterogenous diagnosis. Management of MINOCA should focus on individualizing treatment with cause-specific targeted therapies and institution of cardioprotective therapies for secondary prevention.

\section{References}

1. Tamis-Holland JE, Jneid H, Reynolds HR, Agewall S, Brilakis ES, Brown TM, et.al. Contemporary diagnosis and management of patients with myocardial infarction in the absence of obstructive coronary artery disease: a scientific statement from the American Heart Association. Circulation. 2019; 139: e891-e908.

2. Pasupathy S, Air T, Dreyer RP, Tavella R, Beltrame JF. Systematic review of patients presenting with suspected myocardial infarction and nonobstructive coronary arteries. Circulation. 2015; 131(10): 861-870.

3. Gross H, Sternberg WH. Myocardial infarction without significant lesions of coronary arteries. Arch Int Med. 1939; 64(2): 249-267.

4. Likoff W, Segal BL, Kasparian H. Paradox of normal selective coronary arteriograms in patients considered to have unmistakable coronary heart disease. N Engl J Med. 1967; 276(19): 1063-1066.

5. Eliot RS, Bratt G. The paradox of myocardial ischemia and necrosis in young women with normal coronary arteriograms: Relation to abnormal hemoglobin-oxygen dissociation. Am J Cardiol. 1969; 23(5): 633-638.

6. DeWood MA, Stifter WF, Simpson CS, Spores J, Eugster GS,
Judge TP, et. al. Coronary arteriographic findings soon after Non-Q-Wave Myocardial Infarction. N Engl J Med. 1986; 315 : 417-423.

7. Alpert JS. Myocardial infarction with angiographically normal coronary arteries. Arch Int Med. 1994; 154(3): 265-269.

8. Beltrame JF. Assessing patients with myocardial infarction and nonobstructed coronary arteries (MINOCA). J Intern Med. 2013; 273(2): 182-185.

9. Barr PR, Harrison W, Smyth D, Flynn C, Lee M, Kerr AJ. Myocardial Infarction without obstructive coronary artery disease is not a benign condition (ANZACS-QI 10). Hear Lung Circ. 2018; 27: 165-174.

10. Safdar B, Spatz ES, Dreyer RP, Beltrame JF, Lichtman JH, Spertus JA, et. al. Presentation, clinical profile, and prognosis of young patients with myocardial infarction with nonobstructive coronary arteries (MINOCA): results from the VIRGO study. J Am Heart Assoc. 2018; 7: e009174.

11. Daniel M, Agewall S, Caidahl K, Collste O, Ekenbäck C, Frick M, et. al. Effect of Myocardial Infarction with nonobstructive coronary arteries on physical capacity and quality-of-life. Am J Cardiol. 2017; 120: 341-346.

12. Agewall S, Beltrame JF, Reynolds HR, Niessner A, Rosano G, Caforio ALP, et. al. ESC working group position paper on myocardial infarction with non-obstructive coronary arteries. Eur Heart J. 2017; 38: 143-153.

13. Thygesen K, Alpert JS, Jaffe AS, Simoons ML, Chaitman BR, White $\mathrm{HD}$; the Writing Group on behalf of the Joint ESC/ACCF/AHA/WHF Task Force for the Universal Definition of Myocardial Infarction. Third universal definition of myocardial infarction. Circulation. 2012; 126: 2020-2035.

14. Thygesen K, Alpert JS, Jaffe AS, Chaitman BR, Bax JJ, Morrow DA, et. al. the Executive Group on behalf of the Joint European Society of Cardiology (ESC)/American College of Cardiology (ACC)/American Heart Association (AHA)/World Heart Federation (WHF) Task Force for the Universal Definition of Myocardial Infarction. Fourth Universal Definition of Myocardial Infarction. Circulation. 2018; 138: e618-e651.

15. Reynolds HR, Srichai MB, Iqbal SN, Slater JN, Mancini GB, Feit F, et. al. Hochman JS. Mechanisms of myocardial infarction in women without angiographically obstructive coronary artery disease. Circulation. 2011; 124: 1414-1425.

16. Vergallo R, Ren X, Yonetsu T, Kato K, Uemura S, Yu B, et. al. Pancoronary plaque vulnerability in patients with acute coronary syndrome and ruptured culprit plaque: a 3-vessel optical coherence tomography study. Am Heart J. 2014; 167: 59-67.

17. Beltrame JF, Crea F, Kaski JC, Ogawa H, Ong P, Sechtem U, et. al. Coronary Vasomotion Disorders International Study Group (COVADIS). International standardization of diagnostic criteria for vasospastic angina. Eur Heart J. 2017; 38(33): 25652568.

18. Prinzmetal M, Kennamer R, Merliss R, Wada T, Bor N. Angina pectoris I. A variant form of angina pectoris: Preliminary report. Am J Med. 1959; 27: 375-388.

19. Montone RA, Niccoli G, Fracassi F, Russo M, Gurgoglione F, 
Cammà $\mathrm{G}$, et. al. Patients with acute myocardial infarction and non-obstructive coronary arteries: safety and prognostic relevance of invasive coronary provocative tests. Eur Heart J. 2018; 39: 91-98.

20. Saw J, Humphries K, Aymong E, Sedlak T, Prakash R, Starovoytov A, et. al. Spontaneous Coronary Artery Dissection: Clinical outcomes and risk of recurrence. J Am Coll Cardiol. 2017; 70(9): 1148-1158.

21. Gard A, Lindahl B, Batra G, Hadziosmanovic N, Hjort M, Szummer KE, et. al. Interphysician agreement on subclassification of myocardial infarction. Heart. 2018; 104(15): 1284-1291.

22. Nestelberger T, Boeddinghaus J, Badertscher P, Twerenbold R, Wildi K, Breitenbücher D, et. al. Effect of definition on incidence and prognosis of type 2 myocardial infarction. J Am Coll Cardiol. 2017; 70(13): 1558-1568.

23. Reynolds HR, Maehara A, Kwong RY, Sedlak T, Saw J, Smilowitz NR, et. al. Coronary Optical Coherence Tomography and Cardiac Magnetic Resonance Imaging to determine underlying causes of MINOCA in women.

Circulation. 2020. Nov $14 . \quad$ doi: 10.1161/CIRCULATIONAHA.120.052008. *Online ahead of print.

24. Choo EH, Chang K, Lee KY, Lee D, Kim JG, Ahn Y, et. al; KAMIR-NIH Investigators. Prognosis and predictors of mortality in patients suffering myocardial infarction with non- obstructive coronary arteries. J Am Heart Assoc. 2019; 8: e011990

25. Xing L, Yamamoto E, Sugiyama T, Jia H, Ma L, Hu S, et. al. EROSION Study (Effective Anti-Thrombotic Therapy Without Stenting: Intravascular Optical Coherence Tomography-Based Management in Plaque Erosion). Circ Cardiovasc Interv. 2017; 10(12): e005860.

26. Chahine RA, Feldman RL, Giles TD, Nicod P, Raizner AE, Weiss RJ, et. al. Randomized placebo-controlled trial of amlodipine in vasospastic angina. J Am Coll Cardiol. 1993; 21(6): 1365-1370.

27. Yasue H, Takizawa A, Nagao M, Nishida S, Horie M, Kubota $\mathrm{J}$, et. al. Long-term prognosis for patients with variant angina and influential factors. Circulation. 1988; 78: 1-9.

28. Lindahl B, Baron $\mathrm{T}$, Erlinge D, Hadziosmanovic N, Nordenskjold A, Gard A, et. al. Medical therapy for secondary prevention and long-term outcome in patients with myocardial infarction with nonobstructive coronary artery disease. Circulation. 2017; 135: 1481-1489.

29. Nordenskjold AM, Agewall S, Atar D, Baron T, Beltrame, J, Bergstrom $\mathrm{O}$ et.al. Randomized evaluation of beta blocker and ACE-inhibitor/angiotensin receptor blocker treatment in patients with myocardial infarction with non-obstructive coronary arteries (MINOCA-BAT): Rationale and design. Am Heart J. 2021; 231: 96-104.
This work is licensed under Creative Commons Attribution 4.0 License

To Submit Your Article Click Here: Submit Article

DOI:10.31579/2641-0419/106
Ready to submit your research? Choose Auctores and benefit from:

$$
\begin{aligned}
& \text { * fast, convenient online submission } \\
& \text { * rigorous peer review by experienced research in your field } \\
& \text { * rapid publication on acceptance } \\
& \text { * unthors retain copyrights } \\
& \text { * immediate, unrestricted online access }
\end{aligned}
$$

At Auctores, research is always in progress.

Learn more www.auctoresonline.org/journals/clinical-cardiology-andcardiovascular-interventions 